\title{
The Effect of Ti Doping on the Electrochemical Performance of Lithium Ferrite
}

\author{
Keqiang Ding ${ }^{1, *}$, Jing Zhao ${ }^{1}$, Mian Zhao ${ }^{2}$, Yuying Chen ${ }^{1}$, Yongbo Zhao ${ }^{1}$, Jinming Zhou ${ }^{1, *}$ \\ ${ }^{1}$ College of Chemistry and Materials Science, Hebei Normal University, Shijiazhuang 050024, P.R. \\ China \\ ${ }^{2}$ Huihua College of Hebei Normal University, Shijiazhuang 050091, P.R. China \\ *E-mail: kkeqiang@263.net, zhoujm@iccas.ac.cn
}

doi: $10.20964 / 110402513$

Received: 28 January 2016 / Accepted: 17 February 2016 / Published: 1 March 2016

\begin{abstract}
For the first time, a novel composite anode material of titanium (Ti)-doped lithium ferrite (denoted as Ti/LFT) was successfully prepared under air conditions by a high temperature solid state reaction. In this work, the influence of Ti:Fe atomic ratio on the electrochemical performance of the produced Ti/LFT composite was systematically investigated. The crystal structure and morphology of the prepared Ti/LFT composite material were probed by X-ray diffraction (XRD) and scanning electron microscope (SEM). And the electrochemical performance of the resultant materials was chiefly studied by using cyclic voltammetry $(\mathrm{CV})$, electrochemical impedance spectroscopy (EIS) and galvanostatic charge-discharge tests. Results of the electrochemical tests substantially demonstrated that as the atomic ratio of $\mathrm{Ti}$ to $\mathrm{Fe}$ was $1: 8$, the best electrochemical performance was exhibited by the asprepared composite, showing an initial discharge capacity of $761 \mathrm{mAhg}^{-1}$ at the current density of 100 $\mathrm{mAg}^{-1}$ and better rate capability (200 $\mathrm{mAh} \mathrm{g}^{-1}$ at $700 \mathrm{~mA} \mathrm{~g}^{-1}$ ), which was markedly superior to the pure lithium ferrite that was prepared using the same process in the absence of Ti-doping.
\end{abstract}

Keywords: effect; titanium; doping; lithium ferrite; anode material; lithium-ion batteries

\section{FULL TEXT}

(C) 2016 The Authors. Published by ESG (www.electrochemsci.org). This article is an open access article distributed under the terms and conditions of the Creative Commons Attribution license (http://creativecommons.org/licenses/by/4.0/). 